\title{
O PAPEL DA INFERTILIDADE EM NARRATIVAS DE SALVAÇÃO E NARRATIVAS DO FIM
}

\author{
Carolinne Ribeiro Aprachmian ${ }^{1}$
}

\begin{abstract}
RESUMO
Há dois pontos de vista distintos da infertilidade como causadora da extinção ou salvadora da humanidade. O objetivo deste artigo é entender essa percepção e suas consequências sociais nas Narrativas do Fim e nas Narrativas de Salvação, respectivamente em O Conto da Aia, de Margaret Atwood, e Inferno, de Dan Brown. As Narrativas do Fim relatam o fim da humanidade de diversos modos, como guerras nucleares, mudanças climáticas, invasões alienígenas, quedas de meteoros e catástrofes tecnológicas, que podem extinguir a população como um todo ou deixar sobreviventes que anseiam (ou não) reverter a situação. Já as Narrativas de Salvação buscam, propositalmente, reduzir a população mundial com a intenção de recuperar o meio ambiente. Pode-se notar que a infertilidade é vista de forma negativa nas Narrativas de Fim, com consequências sociais extremas na busca pela mudança de estado; já nas Narrativas de Salvação, a infertilidade é inicialmente vista como negativa, porém passa a ser percebida como positiva uma vez que as pessoas envolvidas entendem a finalidade das ações.
\end{abstract}

PALAVRAS-CHAVE: narrativas do fim. narrativas de salvação. infertilidade. O Conto da Aia. Inferno.

There are two possible approaches for infertility as the cause of extinction or salvation of humanity. The purpose of this article is to understand this perception and its social consequences on Narratives of the End and Narratives of Salvation, respectively in The Handmaid's Tale, by Margaret Atwood, and Inferno, by Dan Brown. Narratives of the End are related to the way the world can end in various ways, such as nuclear wars, climate change, alien invasions, meteor strikes and technological catastrophes, which can extinguish all of humanity or leave some survivors who may wish to revert the situation. Narratives of Salvation, in turn, purposefully aim to reduce world population as a way to salvage the environment. It is noted that infertility is perceived as negative in Narratives of the End, with extreme social consequences in the hope of changing the situation; Narratives of Salvation, on the other hand, infertility is initially seen as negative, but becomes positive once people involved in the scenario understand why some actions were taken.

KEY WORDS: narratives of the end. narratives of salvation. infertility. The Handmaid's Tale. Inferno.

Em 1898, Henry James disse que qualquer história fica pior quando acontece com crianças $^{2}$. Mas o quão ruim seria se não houvesse crianças? Inúmeras obras de ficção especulam sobre como seria o futuro da humanidade caso novos nascimentos se tornassem escassos, ou até mesmo não ocorressem mais. Há duas possíveis percepções sobre a infertilidade ou a queda na taxa de natalidade: a abordagem positiva, que considera o declínio populacional como salvação da humanidade, aqui chamada de Narrativa de Salvação; e a abordagem negativa, que considera a queda na taxa de natalidade como possível extinção dos humanos, a Narrativa do

\footnotetext{
${ }^{1}$ Mestranda do Programa de Pós-Graduação em Literatura (PPGL) da Universidade Federal Fluminense (UFF) em Literaturas de Língua Inglesa com foco em Tradução, sob orientação da Professora Doutora Sonia Regina Aguiar Torres da Cruz.

${ }^{2}$ Em referência às histórias contadas em The turn of the screw.
} 
Fim. O uso do termo "Narrativas de Salvação" é feito para diferenciar justamente a percepção da infertilidade. Essas narrativas poderiam ser inicialmente caracterizadas como "de Fim”, mas não o são porque, no final, a infertilidade é aceita como algo positivo ou que trará benefícios para a sociedade. Ambas as Narrativas giram em torno da redução no número de nascimentos - na de Salvação, essa queda é uma consequência, um efeito esperado; na de Fim, é a causa de atos mais drásticos. Um ponto em comum entre elas é que essas histórias costumam acontecer "no contexto e simbolismo do cristianismo"3 (VASSALLO; GRECH, s.d., p. 169), seja por serem ambientadas em sociedades cristãs ou estarem permeadas por imagens religiosas. $\mathrm{O}$ objetivo deste artigo é observar as diferenças no tratamento da fertilidade nessas Narrativas. Para isso, será feita a análise do papel da infertilidade nas obras Inferno, de Dan Brown, e $O$ Conto da Aia, de Margaret Atwood. Essas obras foram escolhidas por serem de fácil acesso, terem visibilidade no mercado e alcançarem um grande público; o atual sucesso do livro de Atwood após a adaptação para série de televisão e a repercussão que as obras de Brown costumam gerar justamente pelo contraste ciência/religião e sua crítica à Igreja Católica, além das adaptações para o cinema.

As Narrativas de Salvação buscam resgatar o planeta Terra de um colapso causado pelo uso extremo de recursos naturais, ou seja, elas tentam recuperar um planeta que vive o Antropoceno. O Antropoceno, termo cunhado por Paul Crutzen e Eugene F. Stoermer (2000), é a era do humano. A classificação dessa era em relação ao ser humano (antropo-) e não em relação à natureza mostra como a humanidade está alterando o planeta. As mudanças climáticas, a poluição e a extinção de espécies são algumas das características que marcam o Antropoceno, que teve seu início quando a humanidade descobriu que poderia usar a $\mathrm{T}(\mathrm{t})$ erra a seu favor. $\mathrm{O}$ marco oficial do surgimento dessa era ocorre no século 19, com a revolução industrial, e há uma grande expansão após a $2^{\text {a }}$ Guerra Mundial. Desde então, os seres humanos têm usado cada vez mais recursos. Por isso, cientistas afirmam que em o planeta está perto de entrar em colapso $^{4}$, e as pessoas sofrerão com a falta de recursos essenciais, como água, comida e ar não poluído. Para evitar que isso aconteça, as Narrativas de Salvação tentam recuperar o planeta. Uma das maneiras de se conseguir isso é reduzindo a população mundial; há dois modos de alcançar esse objetivo: com o extermínio de metade da população atual, como Thanos fez em

\footnotetext{
3 "within the context and symbolism of Christianity".

${ }^{4}$ Veja as publicações disponíveis em:

$<$ http://www.ihu.unisinos.br/78-noticias/588966-o-colapso-da-terra-esta-cada-vez-mais-proximo>,

$<$ https://www.ecycle.com.br/component/content/article/35/1217-o-planeta-a-beira-de-um-colapso.html $>$ e

$<$ https://canaltech.com.br/meio-ambiente/fisicos-teoricos-preveem-colapso-da-humanidade-em-40-anos-

169058/>. Acesso em: 10 fev. 2021.
} 
Vingadores: Guerra Infinita (2018), e com a queda na taxa de natalidade, com um número maior de mortes do que nascimentos até que o equilíbrio planetário seja atingido. Com menos nascimentos, há uma estabilidade populacional que culmina no uso ideal de recursos naturais. Uma das formas de alcançar a queda na taxa de natalidade nesses cenários é a infertilidade compulsória, realizada principalmente por meio da contaminação por vírus.

Em Inferno, do autor norte-americano Dan Brown, o famoso professor de História da Arte Robert Langdon acorda em um hospital de Florença sem qualquer lembrança de como chegou lá. As únicas informações que ele tem são que sua busca está relacionada a Dante Alighieri e a uma possível doença letal, e que ele está sendo caçado. Com a ajuda da médica Sienna Brooks, ele parte em busca da verdade e de sua memória, reconstruindo o quebra-cabeça de dois dias inteiramente perdidos, enquanto escapa das pessoas que estão atrás dele. Tudo isso ocorre em um cenário repleto de museus, obras de arte e simbolismos, já característico das obras de Dan Brown. Inferno é permeado por referências à Divina Comédia, de Dante Alighieri, em que o próprio Dante parte em uma jornada pelo inferno, passando pelo purgatório, até chegar ao paraíso. Assim como a obra italiana, o livro de Brown também traz um forte vínculo religioso, principalmente relacionado aos conceitos de salvação e pestilência.

$\mathrm{Na}$ Bíblia, a pestilência (também chamada de praga) é usada como sinal do julgamento de Deus sobre um grupo de pessoas ou uma nação. As dez pragas do Egito, usadas como punição pela escravização do povo hebreu, são apenas uma das várias ocorrências de pestilências na Bíblia. Em Inferno, o suposto antagonista, o cientista Bertrand Zobrist, acredita ser um mensageiro de Deus, fazendo a vontade Dele: “A obra-prima por mim concebida é uma criação do próprio Deus... um presente Daquele que me imbuiu do intelecto, das ferramentas e da coragem necessários para forjar tal criação” (BROWN, 2013, p. 271). É em busca da salvação que o cientista cria o que se imagina ser uma ameaça grande à população do planeta, um vírus de efeito desconhecido. Zobrist é o deus que cria uma pestilência boa (infertilidade) para acabar com a pestilência que ele pensa ser a ruína da humanidade (fertilidade e suas consequências, excesso populacional, fome, epidemias, guerras). A fertilidade é tratada como uma das pragas da humanidade, assim como a tuberculose é descrita no texto de Gomel (2000, p. 423), como "uma doença debilitante, [que] produz uma narrativa entrópica de morte lenta,

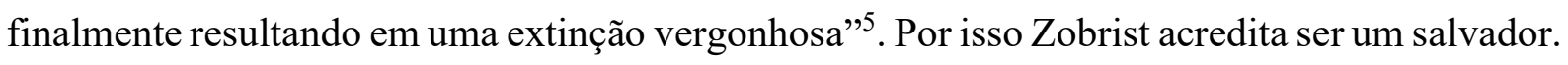

\footnotetext{
5 The second, a wasting contagion, produces an entropic narrative of slow dying, finally petering away into ignominious extinction.
} 
Queridíssimo Deus, rogo-lhe que o mundo se lembre do meu nome não como um pecador monstruoso, mas como o salvador glorioso que o Senhor sabe que na verdade sou. Rogo que a humanidade entenda o presente que deixo./Meu presente é o futuro./Meu presente é a salvação./Meu presente é o inferno. (BROWN, 2013, p. 13, itálico do original)

Ainda no viés religioso, explora-se a questão do expurgo por doenças como uma ação divina, que é relacionada à Peste Negra. Em uma conversa entre Langdon e Sienna, o professor começa "- Saligia representa os pecados coletivos da humanidade, que, de acordo com a doutrinação religiosa medieval.../- Foram o motivo pelo qual Deus puniu o mundo com a Peste Negra - disse Sienna, completando seu pensamento" (BROWN, 2013, p. 61). Como afirma Gomel (2000, p. 407), “A pestilência está na cúspide entre a punição divina e o desastre criado


criado uma praga de extermínio, como a Peste, para transmitir a mensagem divina. Essa ideia é ainda mais corroborada com a revelação feita por Sienna, em que ela diz que:

- [...] a reação mais negativa veio quando ele declarou que seus avanços no campo da engenharia genética seriam muito mais úteis à humanidade se fossem usados não para curar doenças, mas para criá-las. [...] ele afirmava que a sua tecnologia deveria ser utilizada para limitar o crescimento populacional por meio da criação de cepas híbridas de doenças que a medicina moderna seria incapaz de curar. (BROWN, 2013, p. 204, itálico do original)

E como o cientista acreditava que a Peste Negra havia beneficiado a Europa, seu vírus poderia ter mortalidade semelhante, e esse é o medo da OMS, que já o acompanhava e considerava um bioterrorista. Para informar o mundo sobre sua criação, o antagonista preparou um vídeo que deveria ser divulgado em uma data específica, que se supunha ser a data de liberação do vírus. Ele diz:

\begin{abstract}
Séculos atrás, a Europa estava mergulhada em sua própria agonia - a população amontoada, faminta, chafurdando em pecado e desesperança. Era como uma floresta congestionada, sufocada pela matéria em decomposição, esperando que Deus lançasse seu raio - aquela fagulha que finalmente acenderia a chama que iria assolar a terra e desbastar a vegetação excedente e podre, devolvendo a luz do sol às raízes saudáveis./Expurgar é a Ordem Natural de Deus./Perguntem-se: o que veio depois da Peste Negra?/Todos sabemos a resposta./A Renascença./O Renascimento. (BROWN, 2013, p. 50-51)
\end{abstract}

Zobrist, no entanto, não estava sozinho nessa crença, ainda que sua ideia de como alcançar o nível populacional ideal tenha sido amplamente criticada por muitos. Ele havia se tornado um pária na comunidade científica, mas possuía apoiadores. A própria Sienna Brooks, médica, concorda com o cientista que a superpopulação é uma questão problemática, dizendo que "[...] O mundo não vai acabar com fogo, enxofre, apocalipse ou uma guerra nuclear... vai acabar

\footnotetext{
${ }^{6}$ Pestilence is poised on the cusp between divine punishment and man-made disaster.
} 
com um colapso absoluto em decorrência da quantidade de pessoas no planeta. A matemática é indiscutível" (BROWN, 2013, p. 204).

O Antropoceno desperta o interesse do suposto antagonista em criar essa ameaça, inicialmente desconhecida, e poderia ser um dos motivos pelos quais Deus escolhe enviar essa pestilência. Algumas falas de Zobrist deixam claro que é a influência humana no planeta, reforçada pela superpopulação, que pode causar a extinção da humanidade:

Como bem sabe, a Organização Mundial da Saúde voltou a elevar as previsões, calculando que haverá algo em torno de nove bilhões de pessoas na Terra antes da metade deste século. Espécies animais estão entrando em extinção num ritmo aceleradíssimo. A demanda por recursos naturais cada vez mais escassos é astronômica. É cada vez mais difícil encontrar água potável. De acordo com qualquer parâmetro biológico, nossa espécie já excedeu sua sustentabilidade numérica. (BROWN, 2013, p. 102)

Atualmente, há quase oito milhões de pessoas no mundo, o dobro do considerado ideal por Zobrist ${ }^{7}$ (e Thanos). Algumas previsões sugerem que seremos quase dez bilhões até $2050^{8}$ e superaremos esse número até o final do século. No entanto, um estudo da The Lancet ${ }^{9}$ indica que o ápice populacional realmente ocorrerá em 2050/60, mas que, em seguida, a população começará a diminuir. Um dos principais motivos destacados para essa queda é a redução na taxa de natalidade, resultante do maior acesso das mulheres à educação e a métodos contraceptivos. Entretanto, Zobrist não acredita que isso será suficiente para salvar a humanidade, e que será realmente necessário tomar medidas mais drásticas para impedir um futuro sombrio de doenças e fome:

\footnotetext{
${ }^{7}$ Como destacado no trecho a seguir: “- É mesmo? - rebateu Elizabeth, perdendo a paciência. - Então me diga, na sua visão de um futuro sustentável, qual é a população ideal da Terra? Qual é o número mágico que daria à humanidade a esperança de se sustentar de forma indefinida... e com relativo conforto?/O homem sorriu, claramente satisfeito com aquela pergunta./- Qualquer biólogo ou estatístico ambiental lhe dirá que a maior chance de sobrevivência a longo prazo para a humanidade acontece com uma população global de cerca de quatro bilhões de habitantes./- Quatro bilhões? - repetiu Elizabeth. - Nós já estamos em sete bilhões, então é um pouco tarde para isso./Os olhos verdes do homem se incendiaram quando ele perguntou:/- Será?" (BROWN, 2013, p. 105)

${ }^{8}$ Veja <https://brasil.elpais.com/brasil/2016/08/25/ciencia/1472108333_340880.html>. Acesso em: 16 de fev. 2021.

${ }^{9}$ Veja o estudo da The Lancet (em inglês). Disponível em:

$<$ https://www.thelancet.com/action/showPdf?pii=S0140-6736\%2820\%2930677-2>. Acesso em: 16 fev. 2021. Para um resumo sobre o estudo em português, confira a reportagem do El País. Disponível em: $<$ https://brasil.elpais.com/ciencia/2020-07-16/a-humanidade-nao-chegara-aos-10-

bilhoes.html\#: :text=Em\%201800\%2C\%20faz\%20pouco\%20mais, $\% 2 \mathrm{C} \% 20$ superamos $\% 207 \% 2 \mathrm{C} 5 \% 20 \mathrm{bilh} \% \mathrm{C}$ 3\%B5es>. Acesso em: 16 fev. 2021.
} 
O poder da população é tão superior à capacidade da Terra de produzir meios de subsistência para o homem que a morte prematura chegará, de uma forma ou de outra, à raça humana. Os vícios da humanidade agem de forma ativa e eficaz no controle da população. Eles são os precursores do grande exército da destruição e muitas vezes terminam eles próprios o terrível trabalho que iniciam. No entanto, se fracassam nessa guerra de extermínio, moléstias sazonais, epidemias e peste avançam em pavorosa sucessão, ceifando milhares, dezenas de milhares de vidas. Se mesmo assim o sucesso não é alcançado, uma fome colossal e inevitável vem em seguida, nivelando com um golpe poderoso a população mundial à quantidade de comida disponível. (BROWN, 2013, p. 142)

Por isso, ele criou um vírus causador de infertilidade, não uma peste mortal, como se supunha inicialmente. Um vírus seria a escolha lógica por ser um patógeno de propagação rápida. Zobrist usou o "crescimento exponencial do vírus para combater o crescimento exponencial da população" (BROWN, 2013, p. 415, itálico do original). E embora a narrativa tenha cunho altamente religioso, a ciência desempenha um papel crucial. A tecnologia usada por Zobrist é inovadora, um vetor viral. Isso significa que o vírus ataca células do corpo do hospedeiro, não com o objetivo de destruí-las, mas de inserir um novo código genético, modificando a célula. Toda a população global seria infectada, mas somente um terço teria o vírus ativo no organismo. As pessoas não saberiam que tinham sido afetadas, já que não haveria sintomas. No entanto, por ser uma alteração a nível celular, ela seria incorporada e transmitida para os descendentes, "supondo que o vírus tenha pegado, um terço da população mundial agora é estéril... e um terço da população continuará estéril para sempre" (BROWN, 2013, p. 421). Um dos pontos defendidos pelo cientista é que os seres humanos deveriam participar ativamente de sua evolução, seguindo o (controverso) movimento transumanista, que prega que nós deveríamos usar tecnologias de manipulação corporal e genética para nos aprimorarmos enquanto espécie, cada vez mais adaptados ao nosso ambiente. De acordo com Vilaça e Dias (2014), “os transumanistas apostam na mudança da biologia humana como forma de melhorar o humano" (p. 350), tornando-nos pós-humanos, uma espécie nova e aprimorada. Ainda segundo os mesmos autores, uma das definições do transumanismo é que "ele é uma crença na superação das limitações humanas por meio da razão, da ciência e da tecnologia, apoiando as tentativas de eliminar doenças, de melhorar o corpo e a mente, e, no limite, superar até mesmo a morte" (p. 346, itálico do original). A criação de um vírus vetor seria uma tecnologia de grande valor para os transumanistas, ainda que pudesse ser usada tanto para fins positivos quanto negativos. O professor Langdon assume seu estranhamento face à tecnologia desenvolvida: "Um vírus que nos torna estéreis? Sabia que alguns vírus podiam causar esterilidade, mas um patógeno altamente contagioso por via aérea capaz de fazer isso alterando nossos genes parecia ser coisa de outro mundo... uma espécie de distopia do futuro à George Orwell” (BROWN, 2013, p. 420). 
A infertilidade, objetivo dessa Narrativa de Salvação, é bem-vista somente por seu criador e possíveis seguidores; o restante das personagens trata a dita salvação como algo indesejado: “- O que você fez é uma loucura!/Loucura gera loucura./- Pelo amor de Deus gritam eles -, diga-nos onde a escondeu!/É exatamente pelo amor de Deus que não direi" (BROWN, 2013, p. 12, itálico do original). Ela é imposta pelas ações de uma pessoa ou grupo que deseja mudar os rumos do planeta, e, como essa imposição interfere no livre-arbítrio, é vista de forma negativa. Para o professor, "- Isso é terrorismo biológico... - sussurrou Langdon. - É mudar quem nós somos, quem sempre fomos, no nível mais fundamental” (BROWN, 2013, p. 421). Na obra de Dan Brown, a OMS tenta impedir a propagação do vírus de Zobrist por não saber qual será seu efeito. No entanto, assim que descobre a consequência da praga, há uma reviravolta. A própria representante da OMS diz “- Mas é claro que existe uma questão maior. Talvez nós nem queiramos reverter o vírus [...] Se conseguirmos neutralizar o vírus dele sem um plano alternativo viável... vamos voltar à estaca zero" (BROWN, 2013, p. 434), fazendo referência à questão da superpopulação. E, como a infertilidade não acomete todas as pessoas ou há a possibilidade de ser revertida, ela é considerada uma história de salvação, visto que a humanidade não deixará de existir. No fim, ela é aceita, já que o vírus não representa a morte, como inicialmente se pensava, mas um futuro menos populoso e a possibilidade de restauração dos recursos planetários. No entanto, vale ressaltar que essa aceitação parte, a princípio, somente da OMS, uma vez que não é explicitado se essa notícia seria divulgada para o público geral. Assim também acontece na série Utopia (Amazon Studios, 2020), que apresenta um dilema semelhante, há uma personagem que de início queria impedir o plano do antagonista, porém é convencida pelos argumentos e fatos científicos apresentados. Em ambas as obras, poucas pessoas detêm o conhecimento sobre a infertilidade que recairá sobre a humanidade.

Nas Narrativas do Fim, a infertilidade tem causa desconhecida ou é resultante de ações da humanidade, como a poluição ou o uso de armas nucleares e a consequente contaminação por radiação. Por não haver chance aparente ou rápida de modificar esse estado, considera-se uma narrativa sobre o fim da humanidade. É isso que acontece em O Conto da Aia, de Margaret Atwood. Publicada pela primeira vez em 1985, a obra conta a história de Offred, uma aia, mulher que é utilizada para fins específicos de procriação. Após um ataque terrorista exterminar todo o congresso e o presidente dos Estados Unidos, um grupo fundamentalista cristão chamado Filhos de Jacob dá um golpe para assumir o Estado, suspendendo a Constituição. Com o pretexto de restaurar a ordem, eles retiram os direitos das mulheres (impedindo-as de trabalhar e ter contas bancárias, por exemplo) e reestruturam a sociedade. Na nova República de Gilead, 
a sociedade é baseada no Antigo Testamento e dividida em castas, com as mulheres categorizadas em Esposas, Marthas, Aias, Tias. As Esposas eram mulheres casadas com os Comandantes; elas usavam roupas azuis, para representar a Virgem Maria, e a maioria era infértil. As Marthas usavam roupas verdes e eram responsáveis pela manutenção da casa, como governantas. As Tias eram as professoras das Aias, responsáveis pela reeducação dessas mulheres, tornando-as submissas. As Aias usavam roupas vermelhas e tinham o dever de procriar; elas eram as poucas mulheres ainda férteis enviadas para as casas dos Comandantes com o objetivo de terem filhos deles. Mais do que seu trabalho, esse é seu dever moral e religioso.

Ao contrário da Narrativa de Salvação, na Narrativa do Fim a infertilidade é vista como um fator indesejado por um grupo específico. Apesar de ser um problema aparentemente mundial, um dos únicos lugares que se sabe que adotou medidas tão extremas foi Gilead ${ }^{10}$. A narradora afirma ser "importante demais, escassa demais, para isso. Sou uma riqueza nacional" (ATWOOD, 2017, p. 80), referindo-se às poucas mulheres férteis restantes e ao nível de segurança criado para que elas não pudessem escapar. A queda na taxa de natalidade foi um dos fatores que levaram à reestruturação da sociedade. No entanto, não há uma explicação sobre o que levou a essa infertilidade em massa.

Não houve uma causa única, diz Tia Lydia. Está postada na frente da sala, com seu
vestido de cor cáqui, com uma batuta na mão. Desenrolado e estendido na frente do
quadro-negro, onde outrora teria havido um mapa, está um gráfico, mostrando o
coeficiente de natalidade por mil, ao longo de anos e anos: uma encosta escorregadia,
descendo além da linha do zero de reposição, cada vez mais para baixo. (ATWOOD,
2017, p. 137, 138)

Inicialmente, o uso de anticoncepcionais, a entrada cada vez maior das mulheres no mercado de trabalho e a legalização do aborto são culpabilizados pela queda na taxa de natalidade de mulheres caucasianas. No capítulo "Notas históricas", que simula a transcrição de um simpósio sobre Gilead, vários anos após os acontecimentos narrados anteriormente pela Aia, é afirmado que os

homens ocupando altas posições no regime puderam escolher a dedo entre as mulheres que tinham demonstrado ser aptas reprodutivamente ao terem concebido e dado à luz uma ou mais crianças saudáveis, uma característica desejável numa era de índices de natalidade caucasianos em queda livre, um fenômeno observável não só em Gilead, mas também na maioria das sociedades caucasianas do norte na época. (ATWOOD, 2017, p. 357)

\footnotetext{
${ }^{10}$ Com base nas informações que são dadas no livro, não há qualquer indicação de que outros países tenham adotado a gravidez compulsória como forma de retomar o crescimento populacional. O outro local de que se tem conhecimento é a Romênia, que mesmo antes da formação de Gilead proibiu o uso de qualquer método contraceptivo, mas promoveu incentivos financeiros/trabalhistas para as mulheres que tivessem filhos.
} 
Desse modo, pode-se perceber que, a princípio, a infertilidade era desejada por um grupo específico, mulheres caucasianas, que historicamente possuem mais acesso à educação e recursos. No entanto, as mulheres não caucasianas também foram afetadas pela infertilidade involuntária. Por causa das notas históricas, sabemos que houve acidentes, panes e até mesmo sabotagens em usinas nucleares, além de vazamentos de armas químicas e biológicas, escoamento de depósitos de lixo tóxico e uso descontrolado de substâncias nocivas, como herbicidas. Todos esses fatos influenciaram o destino das mulheres de Gilead:

Houve uma época em que o ar ficou carregado demais de substâncias químicas, raios, radiação, a água enxameava com moléculas tóxicas, tudo isso leva anos para pôr em ordem, e enquanto isso elas penetram em seu corpo, se acumulam nas suas células adiposas do corpo. Quem sabe, sua própria carne pode estar poluída, suja como uma praia onde houve um derramamento de petróleo, morte certa para os pássaros marítimos e bebês ainda por nascer. Talvez um abutre morresse se comesse você. Talvez você se ilumine na escuridão, como um relógio de pulso de antigamente. (ATWOOD, 2017, p. 137)

A contaminação resultante da radiação e a poluição causada pela humanidade tornaram boa parte da população infértil. Mesmo antes da instituição de Gilead, já se buscavam alternativas para a concepção, como inseminação artificial, clínicas de fertilidade e barrigas de aluguel. Quando a República de Gilead foi criada, as duas primeiras opções foram abolidas, porque eram consideradas irreligiosas, mas a terceira opção, o uso de barrigas de aluguel, estava pautada na bíblia. Um dos pilares da nova sociedade é o seguinte versículo bíblico:

Vendo, pois, Raquel que não dava filhos a Jacob, teve Raquel inveja da sua irmã, e disse a Jacob: Dá-me fillhos, ou senão eu morro./Então se acendeu a ira de Jacob contra Raquel e disse: Estou eu no lugar de Deus, que te impediu o fruto de teu ventre?/E ela lhe disse: Eis aqui a minha serva, Bilha; Entra nela para que tenha filhos sobre os meus joelhos, e eu, assim, receba filhos por ela. (GÊNESIS, 30:1-3)

Foi com base nele que o papel das Aias foi legitimado. O ritual criado para concepção é semelhante ao descrito na bíblia, as Aias se deitam na cama, com as pernas para fora, apoiando a cabeça no ventre das Esposas, encostadas nelas, segurando suas mãos, para que os bebês sejam gerados em conjunto. Sob o viés religioso, porém, somente as mulheres são culpabilizadas pela infertilidade, era proibido por lei dizer que um homem era infértil. Em uma consulta com o médico, a narradora do livro relata a seguinte conversa:

- A maioria desses velhos não consegue mais ter uma ereção e ejacular - diz ele. Ou então são estéreis./Eu quase engasgo de espanto: ele disse uma palavra proibida. Estéril. Isso é uma coisa que não existe mais, um homem estéril não existe, não oficialmente. Existem apenas mulheres que são fecundas e mulheres que são estéreis, essa é a lei. (ATWOOD, 2017, p. 75) 
A interlocução mostra como o machismo impera nessa sociedade teocrática. Se Jacob (marido de Raquel) não era infértil ${ }^{11}$, também não seriam os homens de Gilead. No entanto, eles foram expostos às mesmas condições ambientais (poluição e radiação) que as mulheres; então seria estranho e mesmo milagroso se os homens não tivessem sido afetados também.

Apesar de serem férteis, nem toda gravidez de uma Aia chega a termo, muitas são interrompidas por abortos espontâneos. Mesmo quando se chega ao parto, ainda há chances de ser um Não-bebê, feto que possui alguma malformação congênita e morre pouco tempo após o nascimento.

A que Ofwarren dará à luz? Um bebê, como todas esperamos? Ou alguma outra coisa, um Não-bebê, com uma cabeça de alfinete ou um focinho como o de um cachorro, ou com dois corpos ou um buraco no coração, ou sem braços, ou com mãos e pés colados como nadadeiras? Não há como saber. (ATWOOD, 2017, p. 136)

Os Não-bebês também são chamados de "retalhadoras", um possível indicativo do que acontecia com os corpos após a morte. ${ }^{12}$

Passar por tudo aquilo e dar à luz uma retalhadora: não era um pensamento nada atraente. Não sabíamos exatamente o que aconteceria com os bebês que não recebiam aprovação, que eram declarados Não-bebês. Mas sabíamos que eram postos em algum lugar, rapidamente descartados. (ATWOOD, 2017, p. 137)

Todos os defeitos de nascimento poderiam ser previstos, porém, nessa sociedade teocrática, a ciência não tem vez. As menções feitas a médicos são em referências à manutenção da saúde das Aias, garantindo sua fertilidade, ou para auxiliar nos partos (em casos extremos) e avaliar a criança após o nascimento. Não é feito um acompanhamento durante a gravidez. Sobre os bebês com defeitos, a narradora diz que "houve um tempo em que eles podiam dizer, com o uso de máquinas, mas isso hoje está banido. De que serviria saber, de qualquer modo? Você não pode mandar tirá-los; seja lá o que for tem que ser levado a termo" (ATWOOD, 2017, p. 136). O aborto é proibido, mesmo que a criança não tenha chances de sobrevivência, colocando a vida da mãe em perigo, já que um parto normal de uma criança que poderia ter duas cabeças ou dois corpos é perigoso. Em uma sociedade infértil, é racional que os abortos sejam proibidos, e mesmo que fossem autorizados "nenhuma mulher de plena posse de suas faculdades mentais, nos dias de hoje, tentaria impedir um nascimento, se tivesse a sorte imensa de conceber" (ATWOOD, 2017, p. 45), principalmente as Aias. No entanto, renegar a ciência em prol da religião é expor essas mulheres a mais perigos. Ainda que as Aias sejam essenciais para a sociedade, elas não são valorizadas enquanto mulheres. Como a narradora diz, "Somos

\footnotetext{
${ }^{11}$ Segundo a bíblia, Jacob teve o total de treze filhos com suas duas esposas e as servas de cada uma. Leia a história de Jacob em: <https://estiloadoracao.com/quem-foi-jaco-na-biblia/>. Acesso em: 19 fev. 2021.

12 No original em inglês são chamados de "shredders".
} 
úteros de duas pernas, apenas isso: receptáculos sagrados, cálices ambulantes" (ATWOOD, 2017, p. 165). Elas são apenas o meio necessário para um fim. Para elas, levar a termo uma gravidez e gerar uma criança saudável era o passaporte para uma vida mais segura, em que não teriam medo de ser enviadas para as Colônias. A fertilidade "é uma bandeira no alto de uma colina que nos mostra o que ainda pode ser feito: também podemos ser salvas" (ATWOOD, 2017, p. 37).

As Colônias são territórios dos antigos Estados Unidos que são palcos de guerras ou foram destruídos e tornados inabitáveis por causa de possíveis ataques nucleares ou derramamentos de substâncias tóxicas. Com a justificativa de tornar esses locais limpos e habitáveis novamente, os Comandantes de Gilead enviam para lá as Não-mulheres: freiras que não quebram seus votos de castidade, mulheres mais velhas, mulheres férteis que se recusam a ser Aias, e homossexuais; basicamente, pessoas que não estão aptas a desempenhar um dos papéis femininos em Gilead, mas que não cometeram crimes graves o suficiente para serem assassinadas, mulheres dispensáveis. Também havia homens nas Colônias, os chamados "Traidores de Gênero" (homossexuais). Supostamente havia um terceiro tipo de colônia onde seria possível ter uma vida razoável e mais saudável sem a exposição quase direta a todas as substâncias e radiação, as de agricultura.

Toda ação tem seu preço, seja nas Narrativas de Salvação ou nas de Fim. "Não fazer nada é o mesmo que acolher o Inferno de Dante... amontoados e famintos, chafurdando em Pecado. Por isso tive coragem de tomar uma atitude. Alguns se encolherão de horror, mas toda salvação tem seu preço. Um dia o mundo irá entender a beleza do meu sacrificio." (BROWN, 2013, p. 334, itálico do original). Em Inferno, o preço da salvação é a esterilidade de um terço da população mundial. Já em $O$ Conto da Aia é a exploração das mulheres ainda férteis, colocando suas vidas em risco caso não fossem capazes de engravidar, mesmo que isso pudesse acontecer por causa da infertilidade masculina. Em uma conversa com a Aia, o Comandante explica indiretamente o preço a ser pago pela restauração da sociedade:

Não se pode fazer uma omelete sem quebrar os ovos, é o que diz. Pensamos que faríamos melhor./Melhor?, digo, em voz baixa, apagada. Como ele pode pensar que isto é melhor?/Melhor nunca significa melhor para todo mundo, diz ele. Sempre fica pior, para alguns. (ATWOOD, 2017, 251)

Ao compararmos a abordagem da infertilidade nas duas Narrativas, nota-se que são inicialmente semelhantes, tratando-a de forma negativa. Entretanto, enquanto a Narrativa de Salvação aceita e, de certa forma, incentiva a queda na taxa de natalidade, a Narrativa do Fim busca revertê-la, mesmo que para isso tenha que recorrer a métodos pouco ortodoxos. 


\section{REFERÊNCIAS BIBLIOGRÁFICAS}

ANTROPO. In: Aulete Digital. Rio de Janeiro: Lexikon Editora Digital, 2008. Disponível em: $<$ http://www.aulete.com.br/antropo->. Acesso em: 25 jan. 2021.

ATWOOD, Margaret. O Conto da Aia. Tradução de Ana Deiró. Rio de Janeiro: Rocco, 2017.

BROWN, Dan. Inferno. Tradução de Fabiano Morais e Fernanda Abreu. São Paulo: Arqueiro, 2013.

CONEGERO, Daniel. Quem foi Jacó na Bíblia? A História de Jacó. Estilo Adoração, s.d. Disponível em: <https://estiloadoracao.com/quem-foi-jaco-na-biblia/>. Acesso em: 20 fev. 2021.

GOMEL, Elaine. The Plague of Utopias: Pestilence and the Apocalyptic Body. In: Twentieth Century Literature. Vol. 46, No. 4, Literature and Apocalypse (Winter, 2000), pp. 405-433 Disponível em: $<$ https://www.jstor.org/stable/827840?seq=1\#metadata_info_tab_contents $>$. Acesso em: 15 nov. 2020.

STEFFEN, Will. The Anthropocene. 2010. (18m15s). Disponível em: $<$ https://www.youtube.com/watch?v=ABZjlfhN0EQ\&list=PLycUGp8wnIAZZP_DrNK3rBF kclV_uu5uc\&index=1>. Acesso em: 25 jan. 2021.

TRANSUMANISMO: você está pronto para conviver com os humanos melhorados? Tecmundo, 2013. Disponível em:

$<$ https://www.tecmundo.com.br/futuro/42395-transumanismo-voce-esta-pronto-paraconviver-com-os-humanos-melhorados-.htm>. Acesso em: 18 fev. 2021.

VASSALLO, C. T.; GRECH, V. E. Extravagant Fiction Today, Cold Fact Tomorrow: The Theme of Infertility in Science Fiction. In: Discourses and Narrations in the Biosciences. Documento eletrônico. Disponível em:

$<$ https://www.academia.edu/10127131/_Extravagant_Fiction_Today_Cold_Fact_Tomorrow_ The_Theme_of_Infertility_in_Science_Fiction>. Acesso em: 23 jan. 2021.

VILAÇA, Murilo Mariano; DIAS, Maria Clara Marques. Transumanismo e o futuro (pós)humano. Physis [online]. 2014, vol. 24, n. 2, p. 341-362. ISSN 1809-4481. Disponível em: $<$ https://doi.org/10.1590/S0103-73312014000200002>. Acesso em: 18 fev. 2021.

\section{FILMOGRAFIA}

UTOPIA. Produção de Gillian Flynn. Estados Unidos: Amazon Studios, 2020.

VINGADORES: Guerra Infinita. Direção de Anthony Russo e Joe Russo. Estados Unidos: Marvel Studios, 2018. 